University of Wollongong

Research Online

Faculty of Engineering and Information

Faculty of Engineering and Information

Sciences - Papers: Part A

Sciences

$1-1-2014$

Training laboratory: Using online resources to enhance the laboratory learning experience

Sasha Nikolic

University of Wollongong, sasha@uow.edu.au

Follow this and additional works at: https://ro.uow.edu.au/eispapers

Part of the Engineering Commons, and the Science and Technology Studies Commons

Research Online is the open access institutional repository for the University of Wollongong. For further information contact the UOW Library: research-pubs@uow.edu.au 


\title{
Training laboratory: Using online resources to enhance the laboratory learning experience
}

\author{
Abstract \\ 2014 IEEE. Technology has enabled students to search and utilize information from a diverse range of \\ sources. One mechanism that students turn to for additional resources is the internet. This paper \\ explores student interaction with an internet resource, called the Training Laboratory. This resource has \\ multiple uses, including: 1 ) the training of laboratory teaching assistants; 2) providing students an \\ opportunity to develop pre-requisite laboratory skills; 3 ) reduce the workload of developing resources \\ when designing laboratory notes; 4 ) reduce the duplication of learning fundamental laboratory skills in \\ multiple subjects; 5) provide a means to share resources to satellite campuses; and, 6) provide a teaching \\ tool to assist laboratory demonstrators. Feedback from students and staff, three years after \\ implementation, indicate that this is an effective resource that has enhanced learning in the laboratory.
}

\section{Keywords}

learning, training, enhance, resources, online, experience, laboratory

Disciplines

Engineering | Science and Technology Studies

\section{Publication Details}

S. Nikolic, "Training laboratory: Using online resources to enhance the laboratory learning experience," in IEEE International Conference on Teaching, Assessment and Learning for Engineering: Learning for the Future Now (TALE 2014), 2014, pp. 51-54. 


\title{
Training Laboratory: Using online resources to enhance the laboratory learning experience
}

\author{
Sasha Nikolic \\ Faculty of Engineering and Information Sciences \\ University of Wollongong, NSW, Australia \\ Email: sasha@uow.edu.au
}

\begin{abstract}
Technology has enabled students to search and utilize information from a diverse range of sources. One mechanism that students turn to for additional resources is the internet. This paper explores student interaction with an internet resource, called the Training Laboratory. This resource has multiple uses, including: 1) the training of laboratory teaching assistants; 2) providing students an opportunity to develop prerequisite laboratory skills; 3 ) reduce the workload of developing resources when designing laboratory notes; 4) reduce the duplication of learning fundamental laboratory skills in multiple subjects; 5) provide a means to share resources to satellite campuses; and, 6) provide a teaching tool to assist laboratory demonstrators. Feedback from students and staff, three years after implementation, indicate that this is an effective resource that has enhanced learning in the laboratory.
\end{abstract}

Keywords- laboratory demonstrator; laboratory resources; online learning; teaching assistants; transnational teaching; video

\section{INTRODUCTION}

Two or more decades ago most universities had a predominantly stable stream of students that progressed through the three or four years of required coursework. The world has since changed, with a multitude of different entry paths now available for domestic and international students, each with its own entry point into the degree. As a consequence, students are increasingly entering the degree with a different alignment of pre-requisite knowledge [1]. The use of online learning opportunities is increasing and can play a major role in bridging any gap in knowledge.

Differences in prerequisite knowledge are significantly noticeable in the engineering laboratory environment. The laboratory plays a very important role in engineering education $[2,3]$. Skills students gain in the laboratory includes the ability to design, construct, analyze, modify, plot, and observe [4]. Laboratory experiments are usually created with the understanding that students have already obtained a satisfactory level of pre-requisite knowledge in the use of various hardware and software. These presumptions, however, can cause significant stumbling blocks for students without these skills.

The use of multimedia and online technologies can help bridge the gap with deficiencies in required knowledge [5]. This includes the ease of searching with Google, or the millions of available videos on YouTube and other specialty sites. Alternatively, it is possible to develop a range of tools in- house in order to provide a custom solution. Developing in house online tools requires substantial time and resources [6].

In a similar fashion, the design of laboratory notes can take a substantial amount of time, if the goal is to produce an experiment that meets student's satisfaction. One way to improve student satisfaction is by providing a good introduction on how to use various software or hardware used in the laboratory [3]. This is usually carried out in the first and/or second experiment to develop fundamental understanding. In many instances the software and hardware may be used in multiple subjects. Complications to the laboratory notes may occur when software or equipment is changed and laboratory notes need to be updated. This can take substantial workload if the resources are individualized across each subject.

In this paper, the learning benefits of an online resource called the Training Laboratory [7] are investigated. This resource was designed and used at the School of Electrical, Computer and Telecommunications Engineering at the University of Wollongong. Student interaction with the resource, benefits to laboratory teaching, and productivity gains are investigated

\section{BACKGROUND AND RELATED WORK}

\section{A. Teaching Assistants}

The idea that sparked the development of the Training Laboratory was the need to improve the training delivered to teaching assistants used in the laboratory, called laboratory demonstrators [8]. Training teaching assistants is important to provide a quality learning experience for students, and this has resulted in many different training programs [3, 9-11].

Student satisfaction of the laboratory demonstrators was low in the school and a training program was implemented to help improve the laboratory learning experience. During the implementation of the program it was noticed that many of the demonstrators had strong theoretical knowledge but were severely lacking in terms of practical skills. This included knowledge on how to use the equipment in the laboratory, as well as an understanding of how to correctly troubleshoot problems. This problem needed to be rectified, because the laboratory is important for the development of hands on skills [12], and it was unacceptable to have demonstrators lacking these fundamental skills. As a result a website was created that 
contained tutorial videos, information and manuals that the laboratory demonstrators could use as preparation material.

\section{B. Pre-Requiste Student Knowledge}

During the period of developing the resources, the school was also in the midst of an expansion of international student numbers. A similar pattern emerged with the international coursework students, as with the international laboratory demonstrators. The students had sound theoretical understanding, but were lacking in practical laboratory skills, already developed by the domestic students. International students can arrive at any stage of the four year undergraduate program. Depending on the university, the level of laboratory skills could differ significantly. This variability of skill was also an issue in the master's coursework subjects.

In Australia multiple path ways are also causing a similar issue. Students can obtain advanced credit for subjects from studies obtained from other universities or colleges [1]. In addition, the program structure for double degrees or other mixed programs can see students undertake courses in a nonstandard order. The resources developed in the Training Laboratory, provides the opportunity for students to catch up pre-requisite laboratory skills.

\section{Laboratory/Resource Design}

Designing laboratory experiments can take significant workload to be effective and increase student satisfaction. In particular developing video resources can be time consuming, but beneficial for learning [6]. The traditional method of developing laboratory notes is that the process is independent. Each subject coordinator would individually (or subject teaching team) go through the process of teaching and providing resources to complete the laboratory. A major drawback to this method is that productivity would be low, as it was common for different subject coordinates to duplicate the creation of resources or instruction. A second problem existed if hardware or software changed, resulting in the need to update the resources. A third problem was it was often hard, to cater for students, that did not have the pre-requisite skills. Finally, advanced students could become bored, and lose interest in an experiment if it was too simple and repeated existing skills.

\section{The Internet}

A substantial amount of resources is currently available on the internet that is free and useful in teaching skills used in the laboratory. With powerful search engines like Google, and extensive video resources on YouTube, students already have a number of pathways to teach themselves practical skills that may be deficient [13]. Finding information in this manner is a very important skill for engineers to have, and learning should always encourage this independent searching. There is however times when resources are wanted to be ad free, quick to navigate to, and delivered in a specific way.

\section{IMPLEMENTATION}

The Training Laboratory website was developed in 2011 and first used by students in 2012. Content is structured in four categories; Equipment, How to Guide (Hardware), How to Guide (Software), and Troubleshooting. The content includes written instructions, videos, user manuals and links to external resources. Over time, more resources have been developed or linked, to provide students a one stop shop to develop laboratory skills. The main page of the Training Laboratory can be seen in Figure 1.

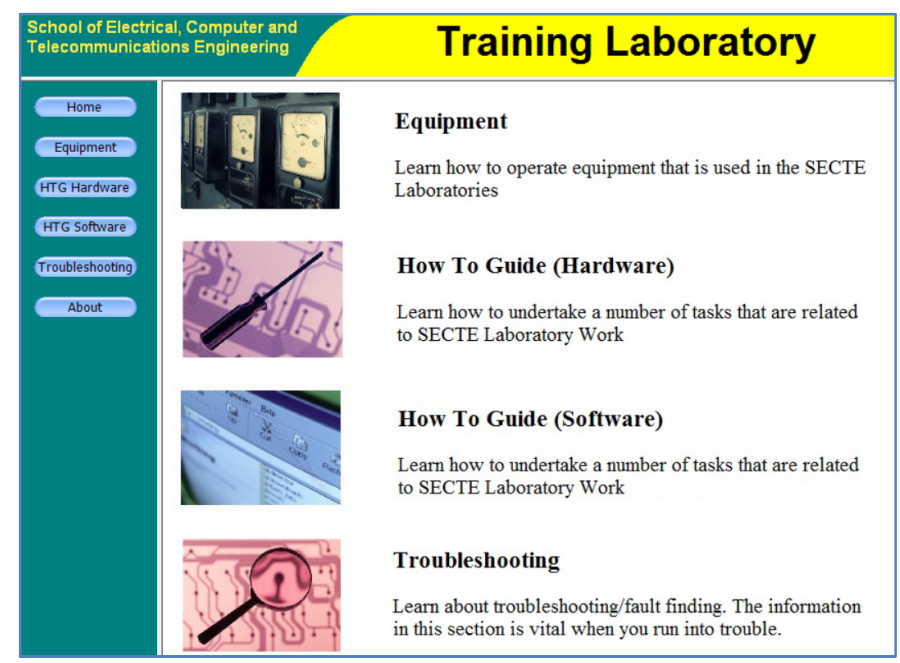

Fig. 1: The Training Laboratory website

The development of each individual resource took a number of days, especially when creating video resources. It took time to develop a plan, undertake the recording, and then edit the video. If a company or website had a well-established training resource a link was provided to prevent unnecessary duplication.

The decision as to what resources where required, and how to design them, was determined by talking to experienced laboratory demonstrators. In particular, it was necessary to identify common student questions. In addition, it was important to identify the common mistakes the students made.

\section{RESULTS}

During 2012 and 2013 the primary method of discovering the benefits, and making improvements, was via a combination of action research and ethnography. During practical experiments the author observed the way in which students used and interacted with the resource, and the way the teaching assistants used it as an educational tool. In addition, feedback was requested from the students and teaching assistants in regards to their experiences with the resource. This feedback was used to alter content, and improve the design of future content. One of the key tools used to measure student feedback was via regular laboratory surveys [3]. Feedback was also sought from subject coordinators to ensure suitability with prelaboratory activities. The following is a summary of early discoveries:

\section{A. Subjects Using The Resource}

The initial site, launched December 2011, was primarily based around resources to support the fundamentals of practical laboratory experiments. This involved videos, written instruction, and instruction manuals on the various equipment used in the practical laboratory. Initial resources also included information on how to make measurements, build circuits and undertake troubleshooting. The resources were capable of 
supporting learning in the laboratory of approximately half of the subjects taught in the school.

The development of resources and links associated with software, and skills such as soldering followed. In particular, the inclusion of a Matlab tutorial in 2013 meant that the resources contained within the website could be of benefit to almost every subject in the school. Matlab is the most heavily used application in the school. If a student arrived at any point in the undergraduate degree, or was starting a Masters by coursework, and did not have prior experience with Matlab, they would be easily pointed to the resource in order to catch up on assumed pre-requisite knowledge.

\section{B. Pre-Laboratory Activities}

The resources used in the Training Laboratory provided an excellent opportunity for use in pre-laboratory activities. In order for students to have a good understanding of the equipment, troubleshooting and other laboratory skills, prelaboratory activities such as quizzes were designed. These activities are primarily targeted at first and second year students. Integrating the Training Laboratory with the prelaboratory activities also provided awareness to students that such resources exist and can be used. Five subjects use the resource for pre lab activities; three electronics related subjects, one digital hardware subject, and one control subject.

\section{Use Within Laboratory Notes}

First and second year laboratory subjects use the Training Laboratory as a reference within the laboratory notes. The advantage of creating an in-house resource is that the subject coordinators know exactly what is available, and know it will be available (won't go offline). When new equipment or software is introduced it is referenced to the Training Laboratory for providing instructions. In most instances the laboratory notes are designed not to teach the specifics of any particular piece of hardware or software. Instead, a link is provided to the student as a resource to gain the required knowledge. The advantage being that there is a reduced chance of different laboratory subjects duplicating learning. Secondly if a student already knows the equipment they do not need to get bored undertaking unnecessary activities. Thirdly, if a student does not have the knowledge, they can actually use the resource to develop the required knowledge.

An example of how the Training Laboratory is integrated into the laboratory notes is shown in Figure 2. The activity is for the students to read a circuit diagram and construct the circuit. If the circuit does not work, and they do not know how to troubleshoot, the students are directed to the resource that teaches them how to undertake that task.

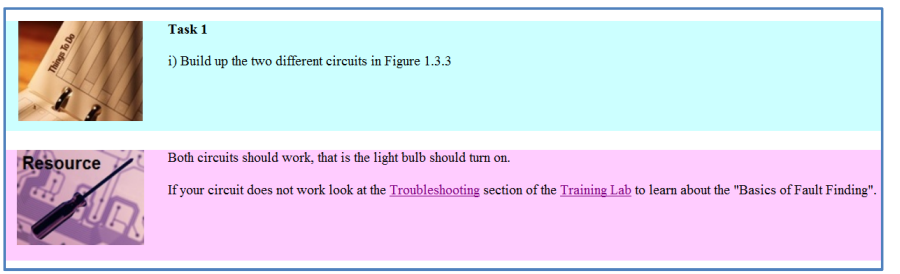

Fig. 2: Example of the Training Laboratory used in laboratory notes

\section{Sharing Internationally}

A common trend with many universities is the establishment of satellite campuses and teaching partnerships with other universities [14]. Currently the school has an offshore campus in Dubai, and two offshore teaching agreements with Chinese universities. A website such as the Training Laboratory provides an effective means to share knowledge and teaching resources. Students at any of the campuses can access the website and learn the fundamental skills in the same fashion as the students studying at the Wollongong campus. In fact, as the resource is open, any student across the world with internet access can take advantage of the available resource.

\section{E. Student Observations}

As expected the Training Lab was of greatest benefit to international students that do not start in the first year of the undergraduate program (equal benefit in first year subjects). A repeated observation, among a number of different laboratories, was that the resource provided the international students an opportunity to make better use of the laboratory time. Entering the laboratory for the first time was no longer a juggle between coming to terms with new foreign equipment/software, and concentrating on the learning objectives of the experiment.

Productivity in the laboratory was observed to be the best when the resources were tied to pre-laboratory activities. Differences in student preparation became noticeable. Students that used the resource were able to progress through the experiments at an increased pace, and resort to the troubleshooting resources without direction, when needed. Students that made little use of the resource wasted time understanding the fundamentals and lacked direction when it came to troubleshooting. When these students struggled the tendency was to seek assistance from the demonstrator, rather than work out how to use resources to find a solution. It usually took the demonstrator a number of attempts to put the students into a routine, in order for them to seek out resources before asking for help.

The students liked the videos most when they were short and to the point. A problem with many of the early videos was a monotone narration of events. Many of the students complained that this caused the video to be very boring, and caused a lack of concentration.

\section{F. Benefits for Teaching Assistants}

The development of the Training Laboratory has been of the greatest benefit to teaching assistants, especially for those that did not undertake any undergraduate studies at the university. The first benefit is in relation to training. International teaching assistants can have less exposure to practical experiments, and if they do have exposure they might not be familiar with the same equipment. The Training Laboratory provides a one stop shop that the teaching assistants can use to learn about the equipment, or refer to when they do not know the answer. 
The second benefit of the Training Laboratory for teaching assistants is the way the website can be used as a tool for learning. If the laboratory demonstrators are asked a question that is covered in the website the first step is to point the students to the relevant resource. For example, the students are unaware of how to measure the current in a circuit with a digital multimeter. The laboratory demonstrator would then show the students the relevant resources available in regards to using the digital multimeter, and how to undertake electrical measurements. This is followed by asking the students if they have reviewed the information contained within the resource.

In most cases the students would not have explored the available resources, or if they had this would help them remember. The laboratory demonstrator would ask the students to review the resource, and that they would return in five minutes to check if they had gained the required level of understanding. This allows the laboratory demonstrator more time to spend with the rest of the class, instead of investing a significant amount of time teaching the fundamental skills. Upon returning to the students, if the appropriate level of understanding had still not been reached, the laboratory demonstrator would be required to identify the issue and help guide the students to the necessary level of understanding.

\section{G. FutureWork \& Early Indicators}

Research commenced in 2014 to quantify the use and benefits of the Training Laboratory. In particular, the amount of time spent using the resource before and during class will be investigated. In addition, the research will try and determine how effective the resource was for student learning.

This research is being conducted through the implementation of pre and post lab survey and quizzes. At the start of each laboratory students are asked questions on how they prepared for the class. They are also asked to complete a simple quiz that tests their preparation. This quiz does not count towards their assessment. At the completion of the laboratory a second survey and quiz is conducted to gain an understanding of what resources were used, and of what benefit the resources had on student learning.

From the research, early indicators in a second year digital hardware subject show that approximately $48 \%$ of students were using the Training Laboratory to prepare for the laboratory class. After the third laboratory class, this percentage would drop quickly as expected. In regards to usage within the laboratory, only six percent of students did not use the resource in the first experiment. By the fourth experiment this climbed to $18.5 \%$. The Training Laboratory is designed to support the fundamentals and is best suited to the first few laboratory experiments.

\section{CONCLUSION}

This paper has shown that the development of a resource, such as the Training Laboratory, to be used in the teaching laboratories has a number of benefits. These benefits are associated with the students in terms of encouraging selfdirected learning skills. In addition, it stops the need for students to be repeating exercises that teach fundamental laboratory skills in multiple subjects.

The benefits of the Training Laboratory to staff include laboratory training and as a resource to help students in the laboratory. In addition, the Training Laboratory simplifies the design of laboratory notes by removing duplication, and by easily being shared across campuses or countries.

[1] T. Millman, "Abridged Too Far? Credit Transfer: Examining the Transition Process from TAFE to University," Australian Journal of Adult Learning, vol. 53, pp. 326-335, 2013.

[2] L. D. Feisel and A. J. Rosa, "The Role of the Laboratory in Undergraduate Engineering Education," Journal of Engineering Education, vol. 94, pp. 121-130, 2005.

[3] S. Nikolic, C. Ritz, P. Vial, M. Ros, and D. Stirling, "Decoding Student Satisfaction: How to Manage and Improve the Laboratory Experience," IEEE Transactions on Education, in press.

[4] I. E. Chika, D. Azzi, A. Hewitt, and J. Stocker, "A Holistic approach to assessing students' laboratory performance using Bayesian networks," in Computational Intelligence in Virtual Environments, 2009. CIVE '09. IEEE Workshop on, 2009, pp. 26-32.

[5] J. Wells, R. M. Barry, and A. Spence, "Using Video Tutorials as a Carrot-and-Stick Approach to Learning," IEEE Transactions on Education, vol. 55, pp. 453-458, 2012.

[6] G. S. Mason, T. R. Shuman, and K. E. Cook, "Comparing the Effectiveness of an Inverted Classroom to a Traditional Classroom in an Upper-Division Engineering Course," IEEE Transactions on Education, vol. 56, pp. 430-435, 2013.

[7] S. Nikolic. (2011, 10/01/14). Training Laboratory. Available: http://secte1.elec.uow.edu.au/traininglab/

[8] S. Nikolic, P. Vial, M. Ros, D. Stirling, and R. Christian, "Improving the Laboratory Experience: A Process to Train \& Manage Teaching Assistants," IEEE Transactions on Education, in press.

[9] C. Park, "The graduate teaching assistant (GTA): lessons from North American experience," Teaching in Higher Education, vol. 9, pp. 349$361,2004$.

[10] J. Lim, M. Kim, S. S. Chen, and C. E. Ryder, "An Empirical Investigation of Student Achievement and Satisfaction in Different Learning Environments," Journal of Instructional Psychology, vol. 35, pp. 113-119, 2008.

[11] D. M. Shannon, D. J. Twale, and M. S. Moore, "TA Teaching Effectiveness: The Impact of Training and Teaching Experience," The Journal of Higher Education, vol. 69, pp. 440-466, 1998.

[12] J. d. 1. H. i. Casas and A. d. B. del Hoyo, "'Learning by doing' methodology applied to the practical teaching of electrical machines," International Journal of Electrical Engineering Education, vol. 46, pp. 133-149, 2009.

[13] D. Y. Lee and M. R. Lehto, "User acceptance of YouTube for procedural learning: An extension of the Technology Acceptance Model," Computers \& Education, vol. 61, pp. 193-208, 2// 2013.

[14] S. Wilkins and M. Balakrishnan, S, "Assessing student satisfaction in transnational higher education," International Journal of Educational Management, vol. 27, pp. 143-156, 2013. 